\title{
الدور الاجتماعي للمرأة السودانية في محاربة العنوسة
}

الدكتور : عبد الرحمن محمد الحسن

جامعة بخت الرضا، السودان

تناول هذا البحث الدور الاجتماعى للمرآة السودانية في محاربة العنوسة

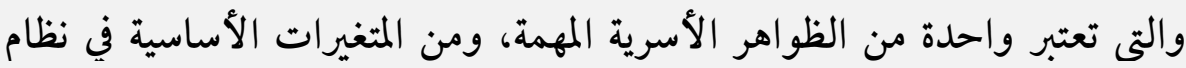

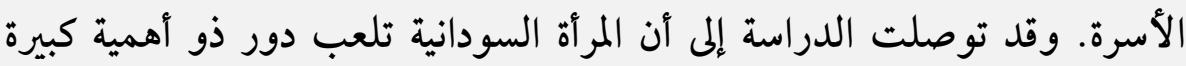
في تقليل ظاهرة العنوسة في المجتمع وذلك من خلال مالك ما تقوم به داخل أسرته

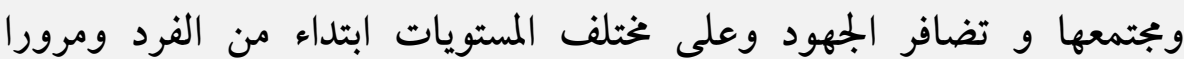
بالأسرة وانتهاءٌ بمؤسسات المجتمع الرسمية والأهلية. وعلئ.

\section{Abstract:}

The present research deals with the role of Sudanese woman in the fight against spinsterhood, which is considered one of the important family phenomena, and one of the fundamental variables in the family system. The study came to the conclusion that the Sudanese woman plays a very important role in reducing the phenomenon of spinsterhood in the community, through what she does within her family and society, and through concerted efforts, at various levels, from the individual to the institutions of official and civil society and via the family. 
ظهور الجغرافيا النسوية و النظرية الأنثوية feminist theory أدى إلى إلى إنيا

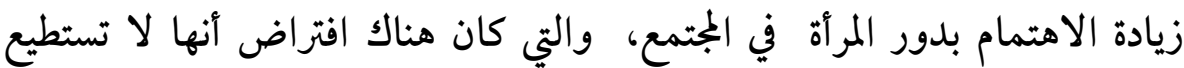

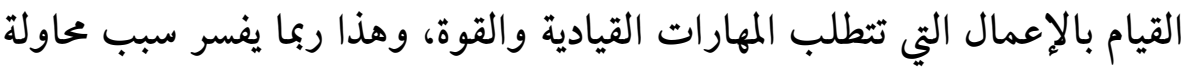

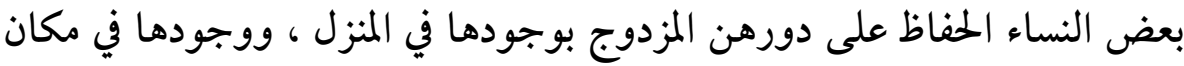

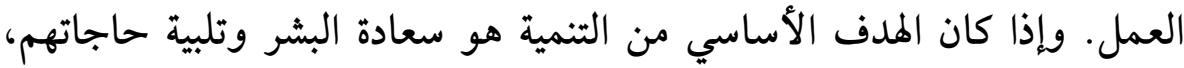

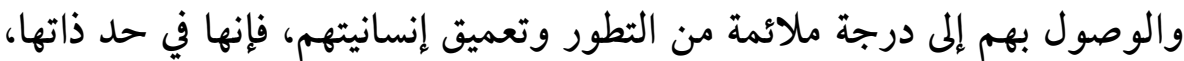
لا تقوم إلا بالبشر أنفسهم الذين هم أهم وسائل تحقيقها.

وفي إطار الاهتمام بقضية التنمية الشاملة، وانطلاقاً من أن التنمية ترتكز

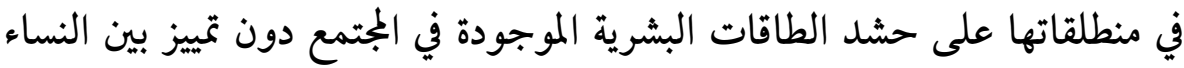

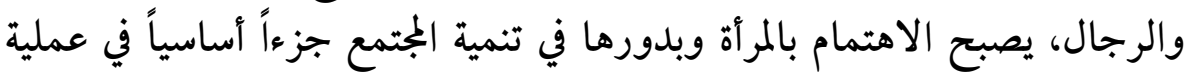

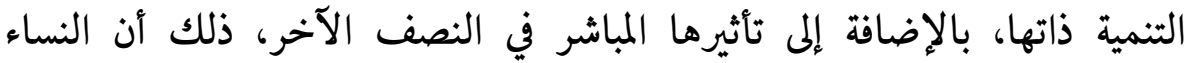

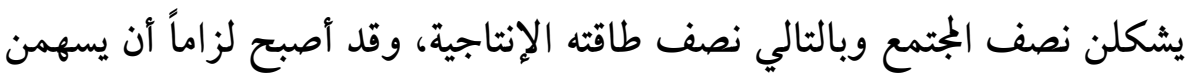

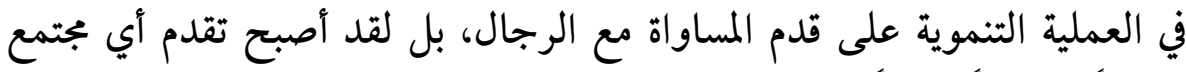

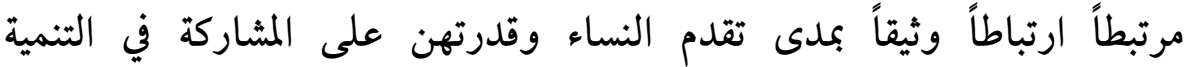

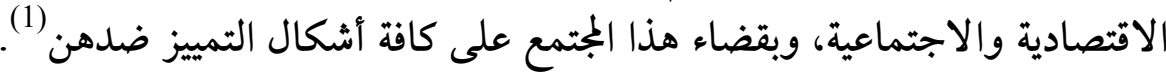
أن مشاركة المرأة في الحياة الاجتماعية رهن بظروف المجتمع الذي تعيش

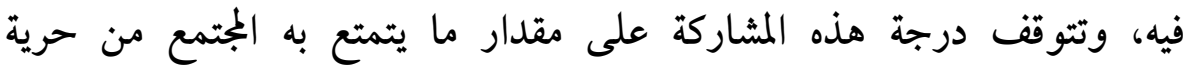

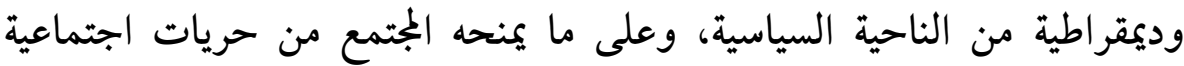

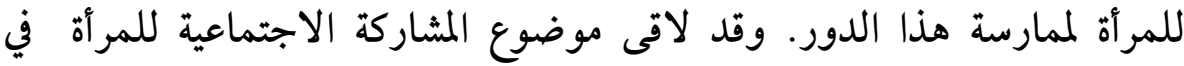

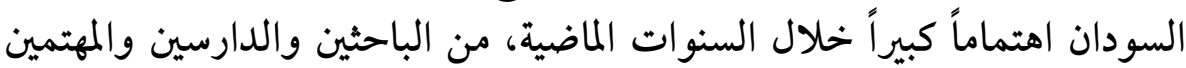

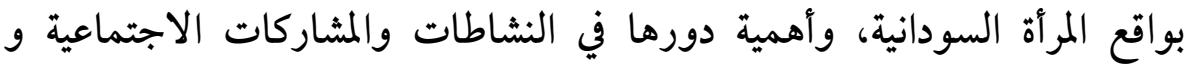

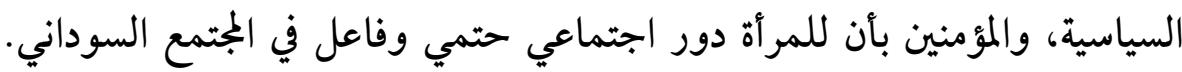
كما هو الحال في دورها الاجتماعي لمحاربة العنوسة. 


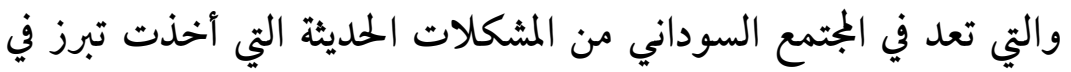

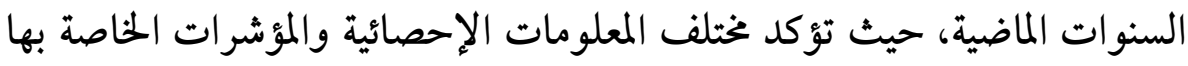

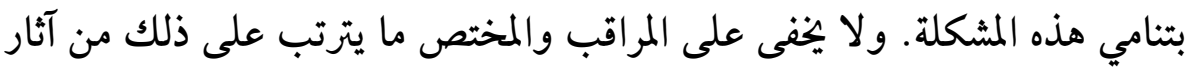

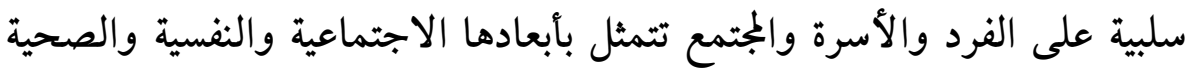

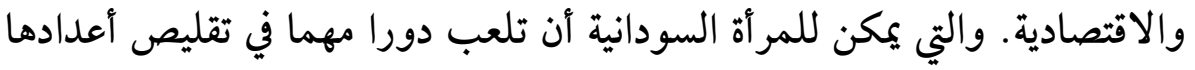
والآثار التي يمكن أن تترتب علئ عليها.

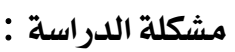
تتمثل مشكلة الدراسة في السؤال الرئيس التالي: هل هل توجد عنوسة في السودان ؟ وتتفرع منه الأسئلة الآتية :

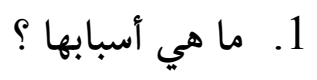

2. ما هو الدور الاجتماعي للمرأة السودانية في محاربتها ؟ العابها

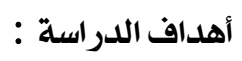

تتناول هذه الورقة الدور الاجتماعي للمرأة السودانية في محاربة العنوسة

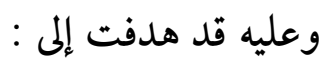

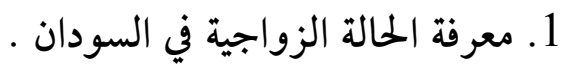

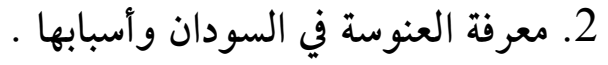
3. التعرف على الدور الاجتماعي الذي يمكن أن تقوم به المرأة في التقليل من

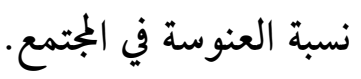

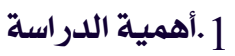

تنبع أهمية الدراسة من أهمية دور المرأة في المجتمع بصفة عامة والمجتمع السوداني بصفة خاصة وذلك لما تقوم به من دور اجتماعي مهم باعتبارها أماً المأ وزوجة وأختاً وبنتاً ومربية أجيال. 
عنست المرأة تعنس بالضم عنوسا وعناسا وتأطرت وهي عانس من نسوة

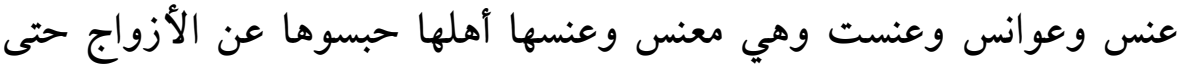

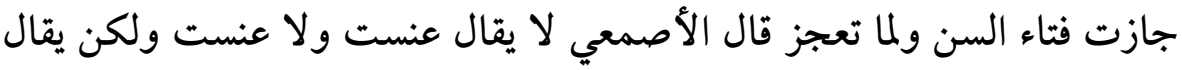

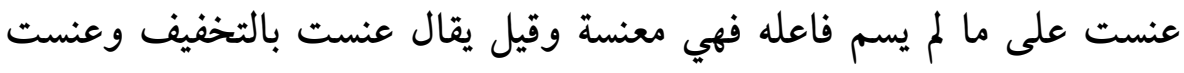

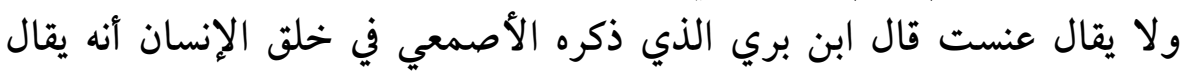

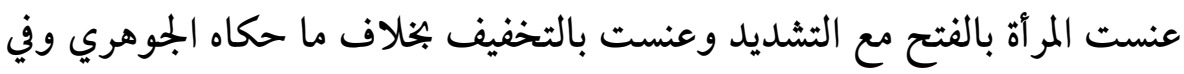

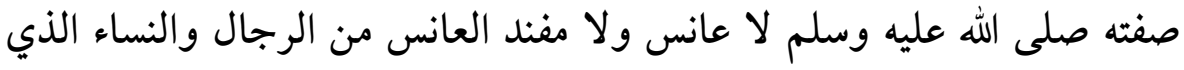

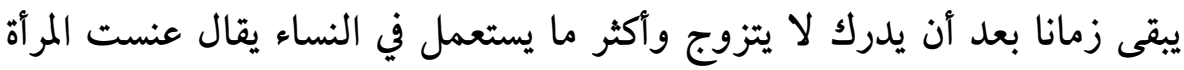

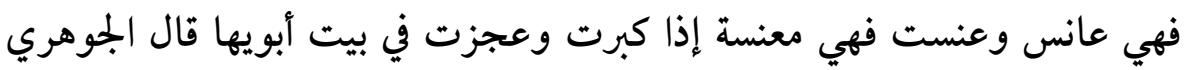

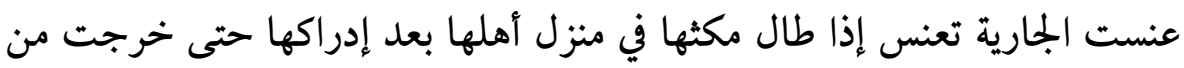

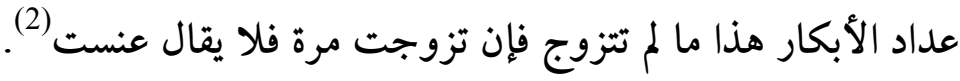

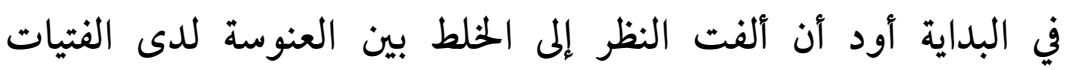

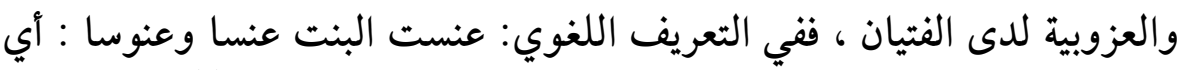

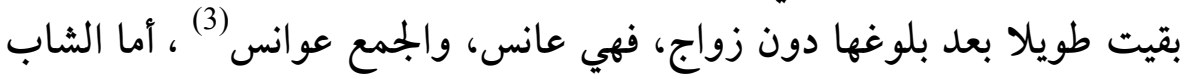

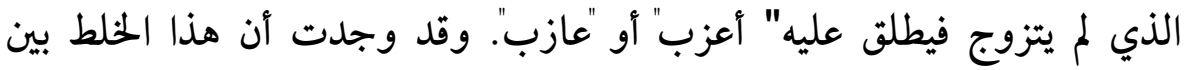

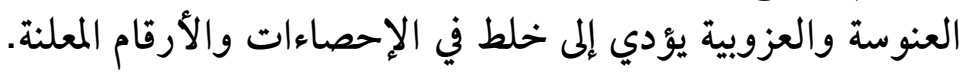

أما العنوسة اصطلاحا ففد عرفها الدكتور محمد خالد منصور بأنها "بقاء

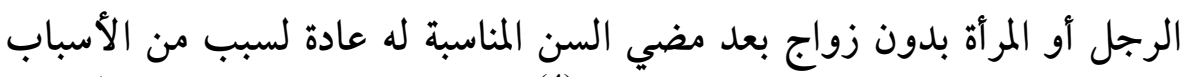

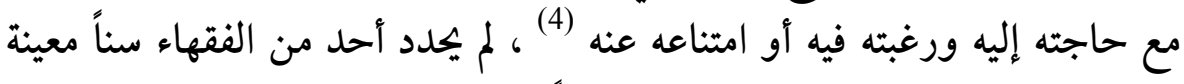

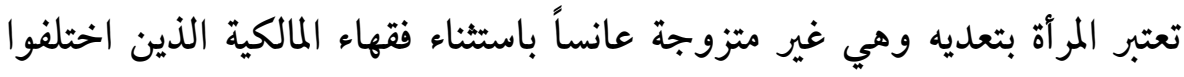

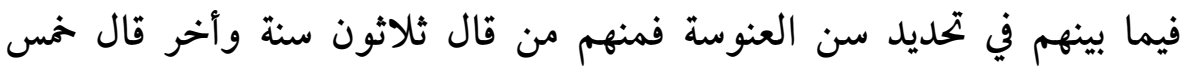

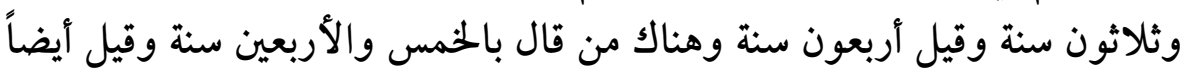


ستون سنة والرأي الراجح أن تحديد سن العنوسة يرجع لعرف الناس ويختلف

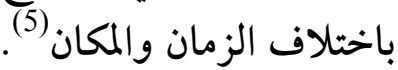

وبذلك لا يكون هنالك سن معينة حتى تعتبر المرأة عانساً وإن مرد ذلك ولك المان

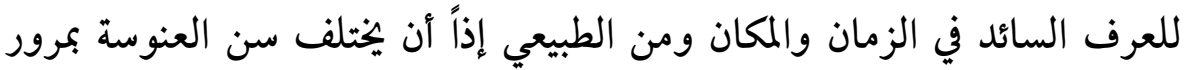

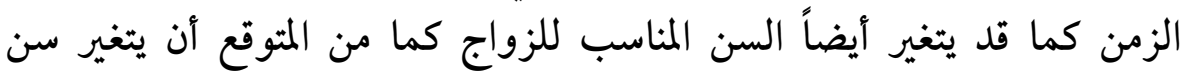

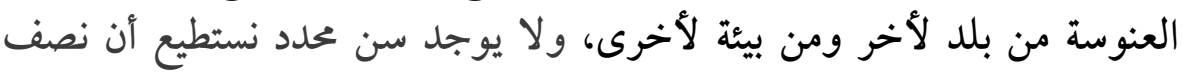

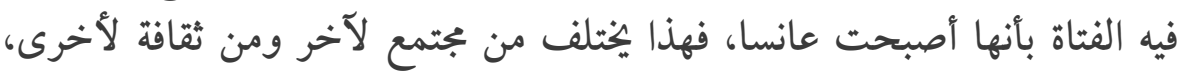

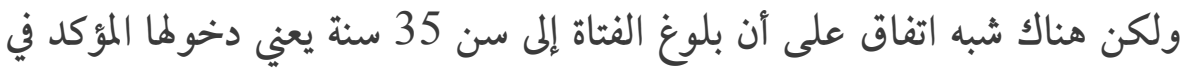

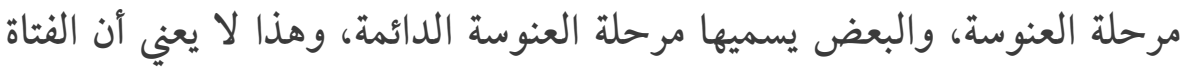

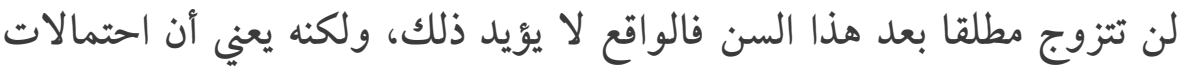

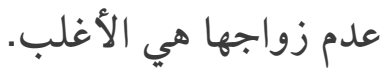

وكثير من الفتيات يرفضن لفظ عانس لما له من ظلال كئيبة ومعان ثقيلة

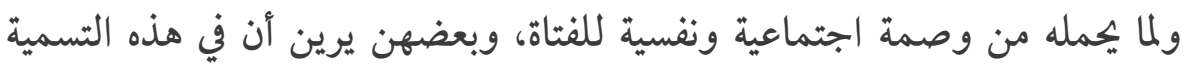

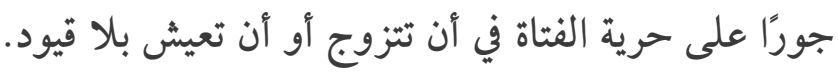

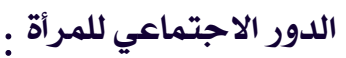

عرفت نادية جمال الدين الدور بأنه مجموعة من الصفات والتوقعات

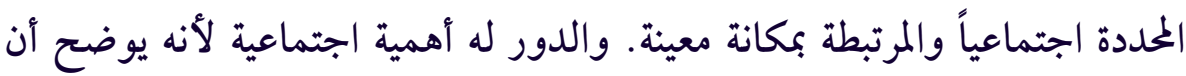

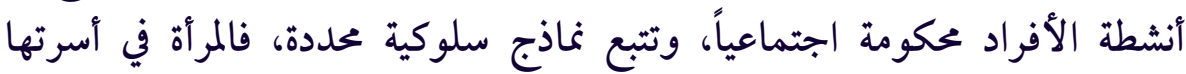

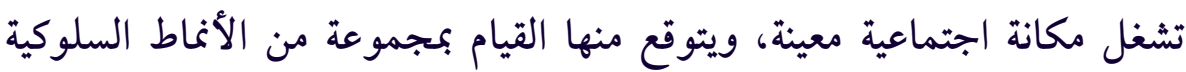

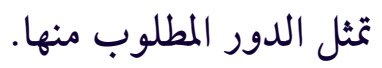

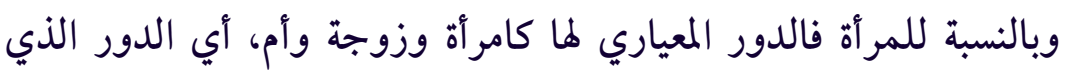

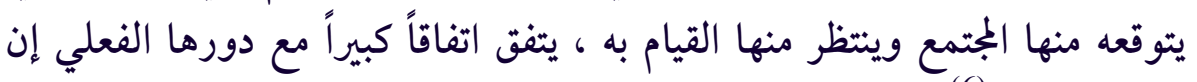
لم يتطابق معه (6) 
تساهم المرأة في المجتمعات الإسلامية والعربية بكل طاقاتها في رعاية بيتها

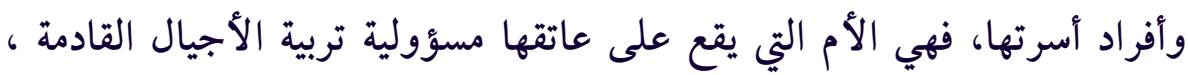

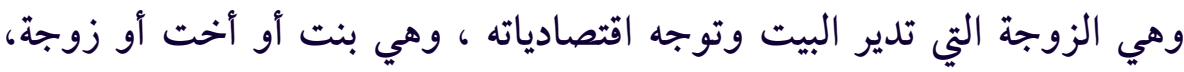

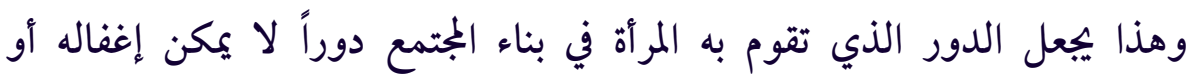

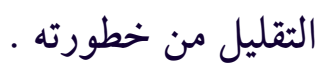

ولذا لا يمكن مناقشة المشاركة الاجتماعية للمرأة بمعزل عن الظروف

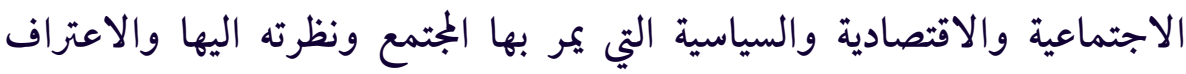

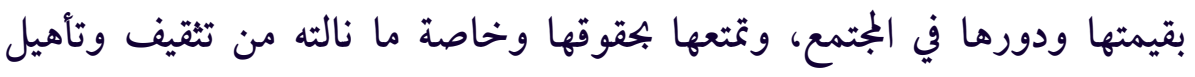

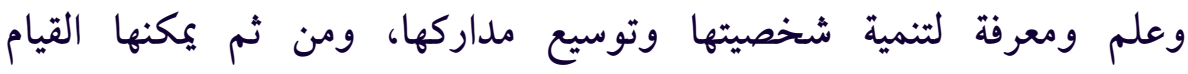
بمسؤولياتها تجاه أسرتها، وعلى دخول ميدان العمل والمشاركة في مجال الخدمة

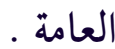

ولكن قدرة المرأة على القيام بهذا الدور تتوقف على نوعية نظرة المجتمع

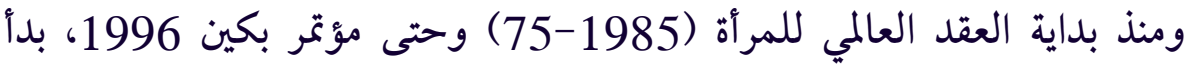

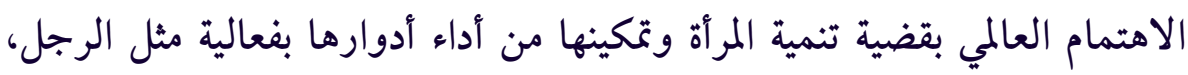

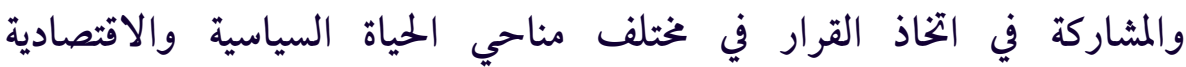

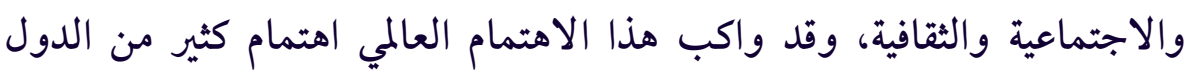

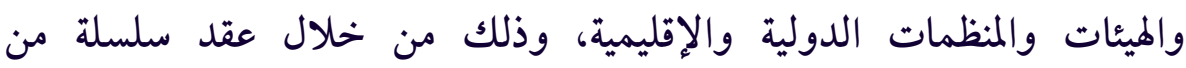
الندوات والمناقشات وورش العمل والمؤتمرات، كان آخرها منتدى قمة المرأة

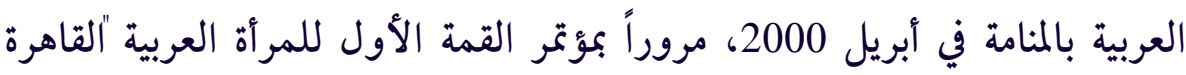

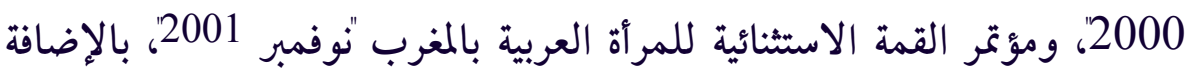


إلى عدة منتديات حول المرأة والسياسة، والمرأة والمجتمع، والمرأة والإعلام، والمرأة والاقتصاد، والمرأة في بلاد المهجر، التي عقدت في عدة دول دول عربية (7).

يرجع اهتمامنا بالدور الاجتماعي والثقافي للمرأة إلى إيماننا بالبيئة التي

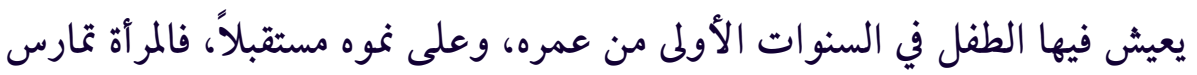

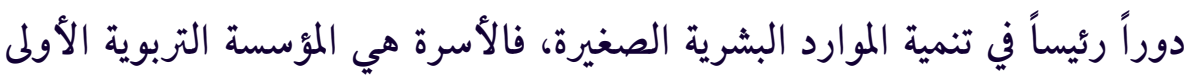

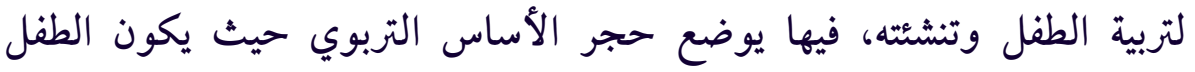
عجينة طيعة يتقبل التوجيه ويلتقط ما يدور حوله من صور وعادات وتقاليد

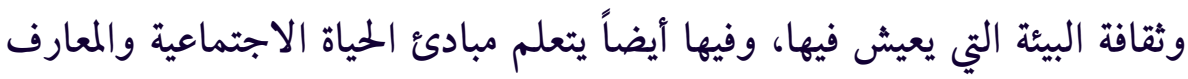

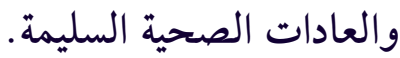

ورعاية المرأة لأبنائها تبدأ قبل ميلادهم، وذلك من خلال اختيارها

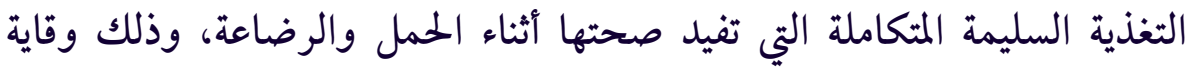

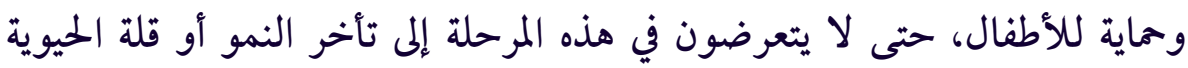

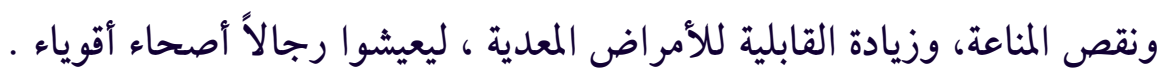

وتنمي المرأة طاقات أبنائها عن طريق إشراكهم في ممارسة الرياضة،

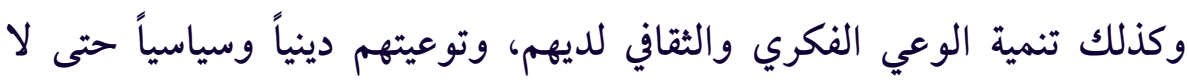

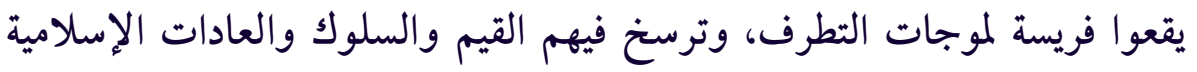

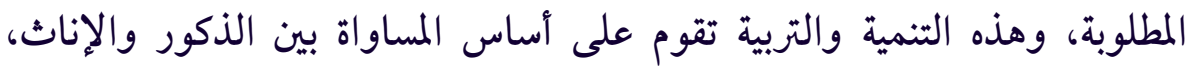

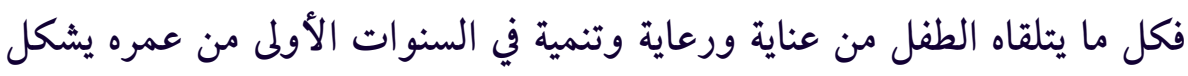

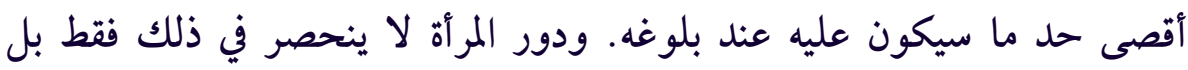

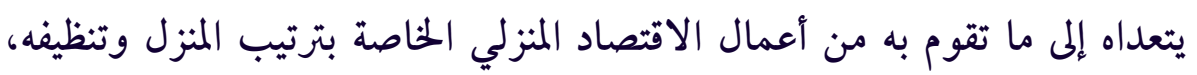




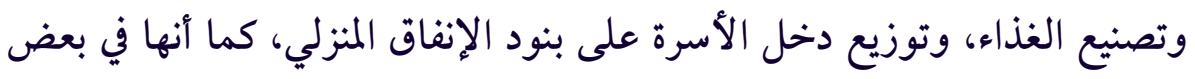

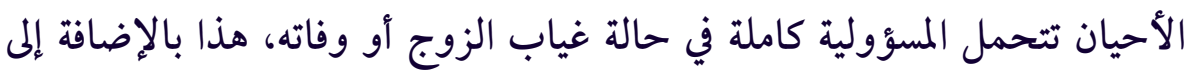

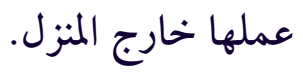

وتعتمد درجة إسهامات المرأة الاجتماعية والثقافية على مدى الخدمات

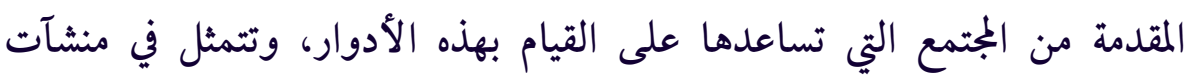

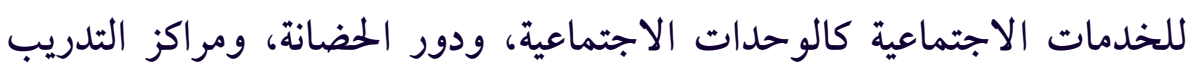

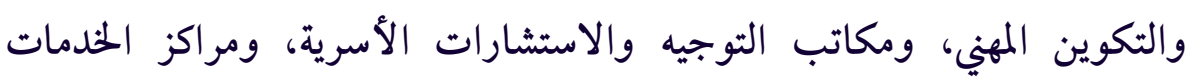

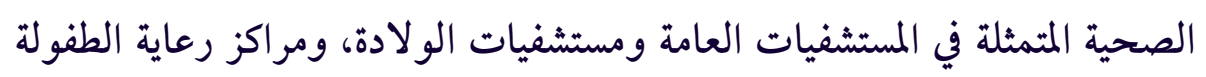

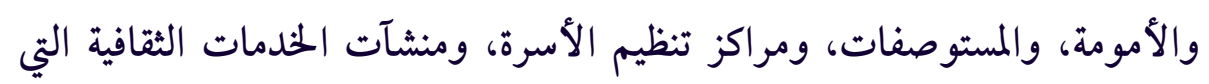

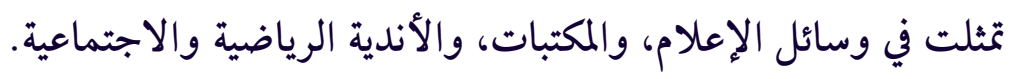

وليست المرأة في حاجة إلى الخدمات فقط، ولكنها في حاجة أيضاً إلى

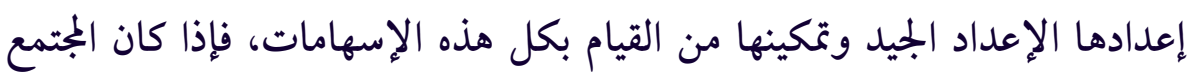

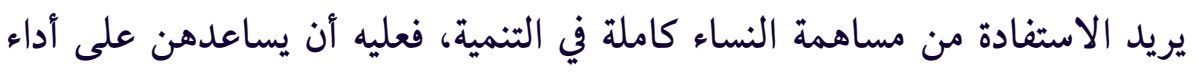

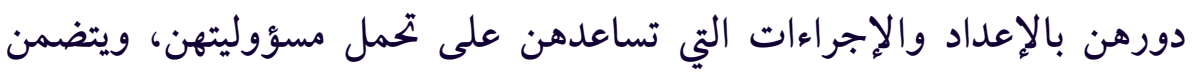

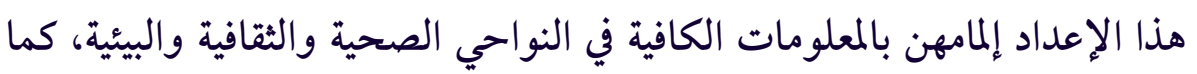

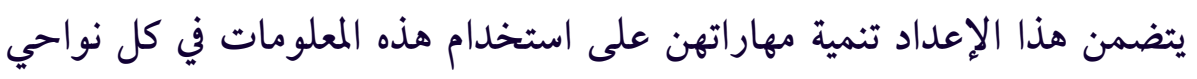

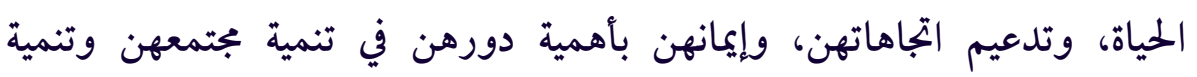

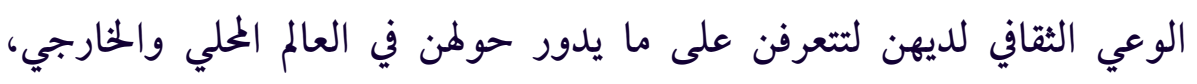

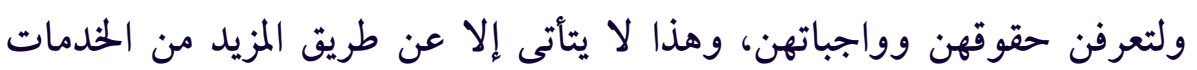
التعليمية والبرامج الثقافية المقدمة للمرأة. 


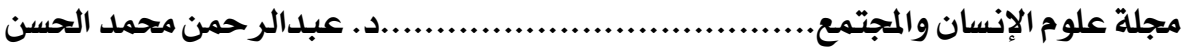

ولقد أكدت وأوصت جميع هذه المنتديات بكافة صورها على ضرورة دعم دور المرأة ومكانتها ومنحها حق العمل في الميادين كافة، انطلاقاً من أهمية مكانة المرأة في المجتمع ودورها في تحقيق استقرار الأسرة.

ويلاحظ ارتفاع معدلات خصوبة المرأة في هذه البلدان، وذلك يرجع إلى العوامل الاجتماعية وعوامل ترتبط بالتراث الثقافي لهذه البلدان، وهذا الحجم

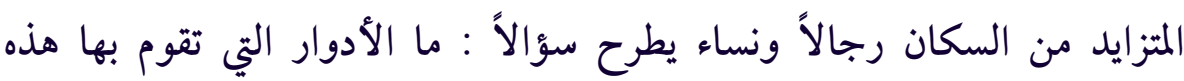
الجموع البشرية من النساء في حاضر المجتمعات وفي مستقبلها ؟ وإلى أي مدى ترتبط هذه الأدوار بما يهيئ لها من فرص الإعداد ووسائله لمواجهة الحياة حتى تتحول من دور واعد بالإمكانية إلى قوة مؤثرة بالفعل، وحتى تصبح طاقة منتجة

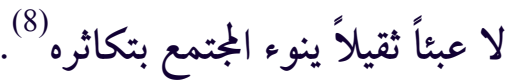
الحالة الزواجية والعنوسة في السودان :

بلغ عدد السكان في السودان حسب تعداد 2008م (39,154,490) نسمة (جدول (1) منهم (19,080,513) نسمة إناث أي 48.73 \% من جملة السكان وهى بذلك تشكل حوالي نصف الجمتمع السوداني. منهن (9429455) نسمة في الفئة العمرية ( 15 - 49 سنه ) ، بنسبة بلغت ( 49.4 ٪ ) من بملة

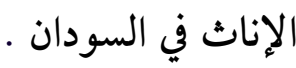


العدد: 05 /مارس/ 2013

جدول (1) يوضح التزكيب العمري للسكان حسب تعداد 2008(9)

\begin{tabular}{|c|c|c|c|}
\hline الإناث & الذكور & الجملة & الفئـة العمرية \\
\hline $19,080,513$ & $20,073,977$ & $39,154,490$ & كل الأعمار \\
\hline $2,840,245$ & $3,005,746$ & $5,845,991$ & 0 to 4 \\
\hline $2,778,173$ & $3,023,603$ & $5,801,776$ & 5 to 9 \\
\hline $2,346,411$ & $2,689,626$ & $5,036,037$ & 10 to 14 \\
\hline $2,024,954$ & $2,151,401$ & $4,176,355$ & 15 to 19 \\
\hline $1,796,936$ & $1,740,076$ & $3,537,012$ & 20 to 24 \\
\hline $1,648,548$ & $1,466,418$ & $3,114,966$ & 25 to 29 \\
\hline $1,295,976$ & $1,207,987$ & $2,503,963$ & 30 to 34 \\
\hline $1,180,296$ & $1,134,069$ & $2,314,365$ & 35 to 39 \\
\hline 868,298 & 905,533 & $1,773,831$ & 40 to 44 \\
\hline 614,447 & 689,233 & $1,303,680$ & 45 to 49 \\
\hline 513,515 & 581,191 & $1,094,706$ & 50 to 54 \\
\hline 285,760 & 350,041 & 635,801 & 55 to 59 \\
\hline
\end{tabular}




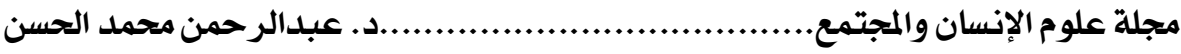

\begin{tabular}{|c|c|c|c|}
\hline 310,256 & 380,847 & 691,103 & 60 to 64 \\
\hline 168,614 & 227,674 & 396,288 & 65 to 69 \\
\hline 185,942 & 229,753 & 415,695 & 70 to 74 \\
\hline 81,003 & 112,065 & 193,068 & 75 to 79 \\
\hline 81,434 & 97,556 & 178,990 & 80 to 84 \\
\hline 26,731 & 38,504 & 65,235 & 85 to 89 \\
\hline 18,018 & 23,528 & 41,546 & 90 to 94 \\
\hline 14,956 & 19,126 & 34,082 & 95 and \\
& & & over \\
\hline
\end{tabular}

الزواج عقد بين رجل وامرأة تحل له شرعاً لتكوين أسرة وإيجاد نسل بينهما،

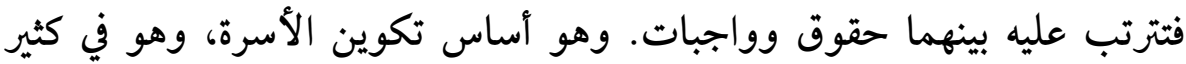
من دول العالم يعتبر مرحلة هامة في الحياة الإنسانية وواجبا اجتماعيا ودينا ودينيا.

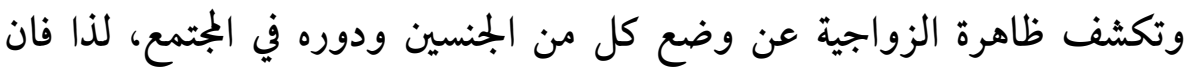

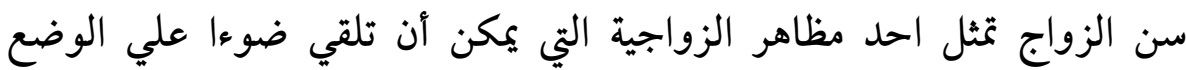

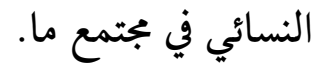

ترتفع نسبة المتزوجات من النساء في السودان حسب الجدول (2) والتي بلغت . \% 52.8 
العدد: 05 /مارس/ 2013

جلول (2) الحالة الزواجية في السودان حسب تعداد 1993 (10)

\begin{tabular}{|c|c|c|c|c|c|c|}
\hline ذكرهم\% لم يتم & والمطلقات & الأرامل ٪ & والمتزوجات ٪ & العازبون & العدد & النوع \\
\hline 0.7 & 1.2 & 1 & 45.3 & 51.8 & 6116140 & ذكور \\
\hline 0.8 & 3.1 & 8.2 & 52.8 & 35.1 & 6375899 & اناث: \\
\hline
\end{tabular}

جدول (3) عدد الزيجات و الطلاق لعامي 2005 و2009(11)

\begin{tabular}{|c|c|c|c|}
\hline نسبة الطلاق & عدد الطلاق & مجموع الزيجات & العام \\
\hline للزواج & & & \\
\hline$\% 41.3$ & 36711 & 88828 & 2005 \\
\hline$\% 43.9$ & 46343 & 105379 & 2009 \\
\hline
\end{tabular}

يمكن الاستدلال عن مؤشرات العنوسة في السودان من خلال العديد من

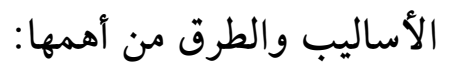

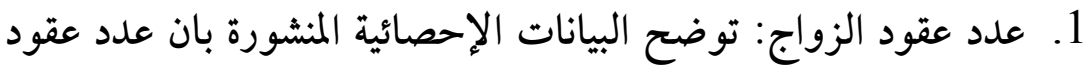

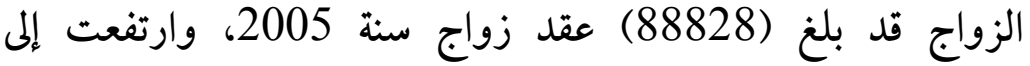

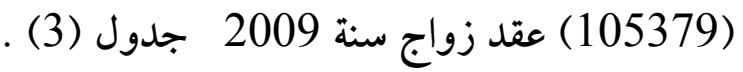

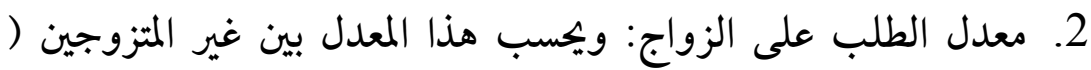

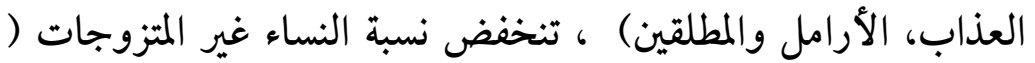

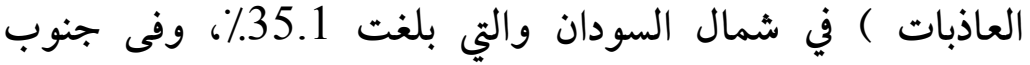

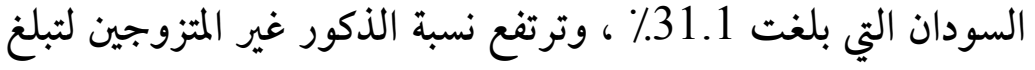

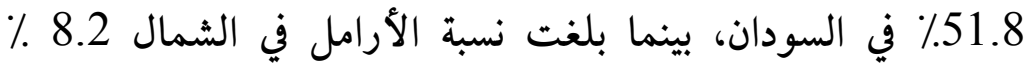

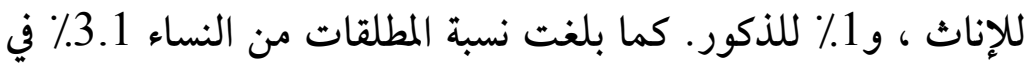
، و1.2\% من المطلقون من الرجال في السودان. 


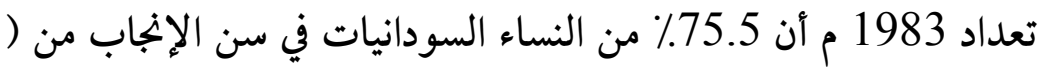

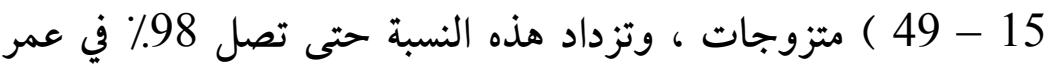

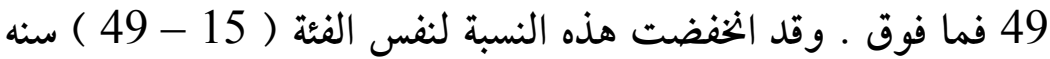

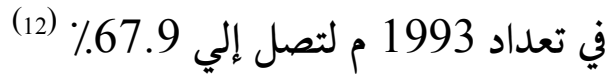

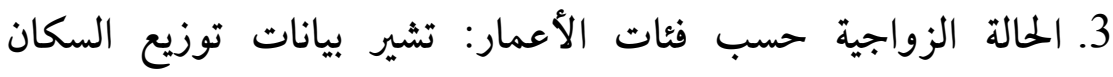

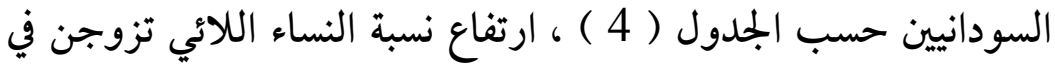

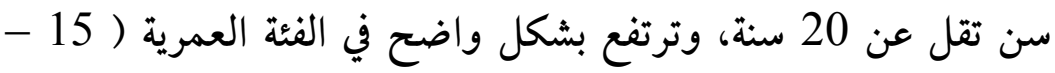

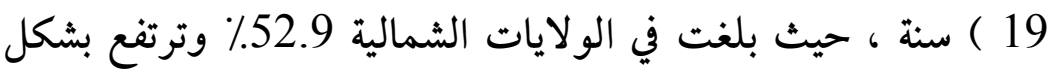

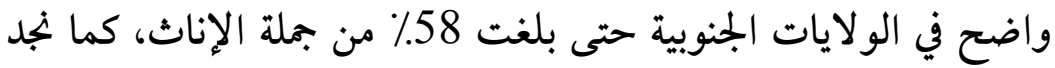

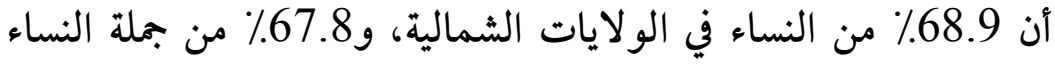

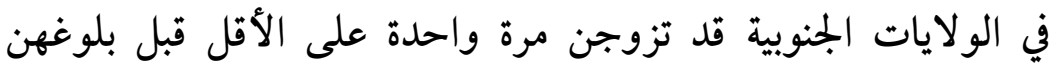

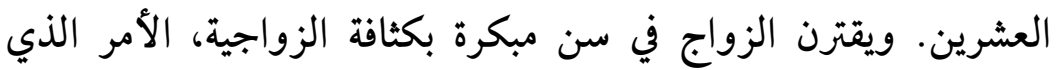

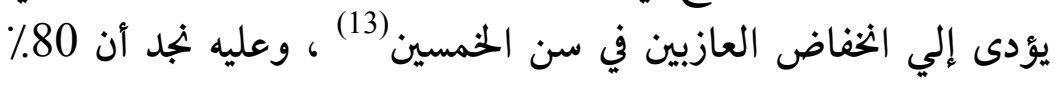

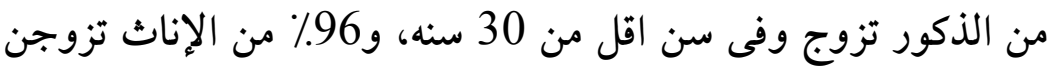

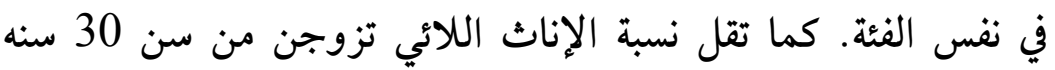
فأكثر والتي بلغت نسبتهن 4\% فقط من نسبة الإناث في السودان.

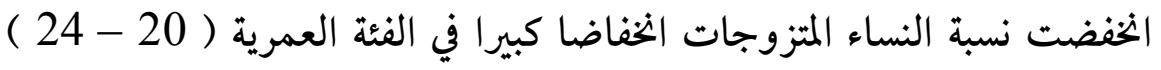

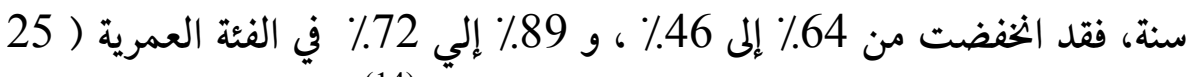

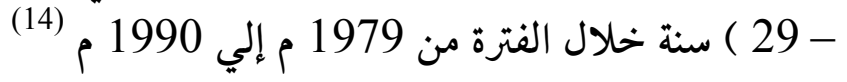


العدد: 05 /مارس/ 2013

جدول ( 4 ) العمر عند الزواج الأول في السودان(15)

\begin{tabular}{|c|c|c|c|c|c|c|c|c|}
\hline$\%$ & الإناث & $\%$ & الأكور & $\%$ & الإناث & $\%$ & الأكور & \\
\hline 100 & 127917 & 100 & 88672 & 100 & 4091505 & 100 & $\begin{array}{r}2903 \\
622\end{array}$ & كل الأعمار \\
\hline 9.5 & 12213 & 0.8 & 704 & 16 & 654804 & 0.7 & $\begin{array}{r}2120 \\
1\end{array}$ & اقل من \\
\hline 58 & 74181 & 5.6 & 13869 & 52.9 & 2163193 & 6.2 & $\begin{array}{r}4698 \\
58\end{array}$ & 19-15 \\
\hline 22.8 & 29150 & 37 & 32869 & 21.6 & 882405 & 53 & $\begin{array}{r}1024 \\
216\end{array}$ & 24-20 \\
\hline 4.6 & 5863 & 28.1 & 24955 & 5.9 & 242509 & 9.3 & $\begin{array}{r}8255 \\
7\end{array}$ & 29-25 \\
\hline 1.6 & 2017 & 15 & 13324 & 1.9 & 76370 & 1.74 & $\begin{array}{r}5042 \\
04\end{array}$ & 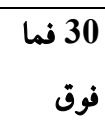 \\
\hline 3.5 & 4491 & 3.3 & 2945 & 1.7 & 72224 & 2 & $\begin{array}{r}5863 \\
7\end{array}$ & ذكرمم لم يتم \\
\hline
\end{tabular}

5.النساء غير المتزوجات في سن الإنجاب: نظرا لان النساء من أكثر الفئات تأثرا

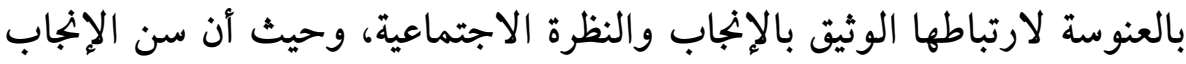

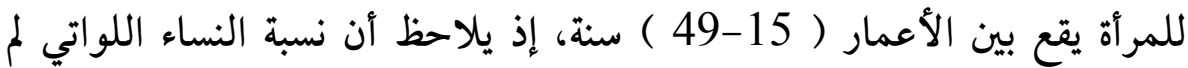

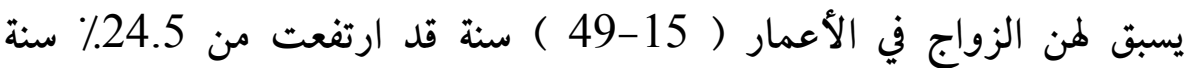

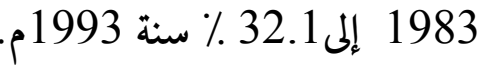

6.متوسط العمر عند الزواج الأول: ويعد ذلك من أهم المؤشرات المامة التي تدل

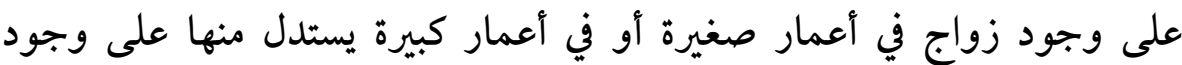


مجلة علوم الإنسان والمجتمع...............................................................

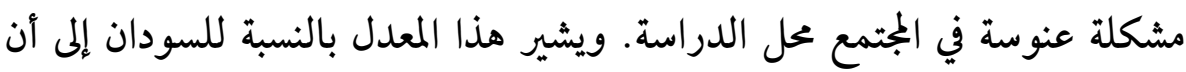

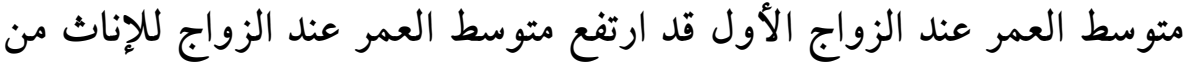

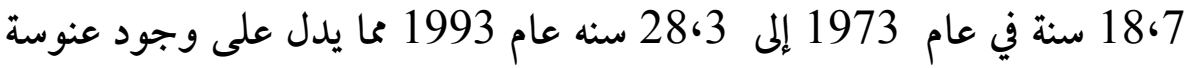
في المجتمع السوداني. 7. هناك فوارق واضحة في سن الزواج في الريف والحضر، حيث بلغت حوالي

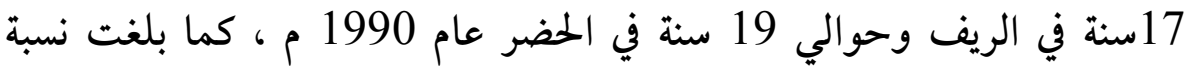

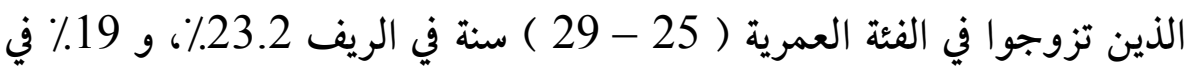

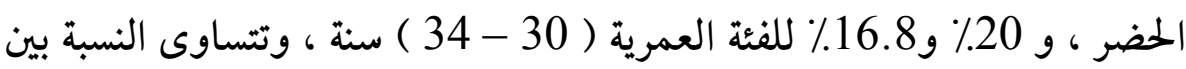

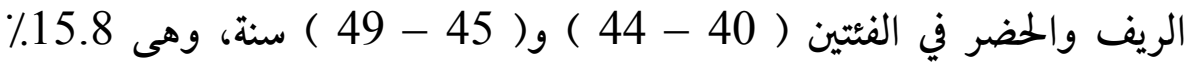
و16.3\% على التوالي.

8. تختلف سن الزواج من ولاية لآخري داخل السودان، فنجدها ترتفع في الولاية

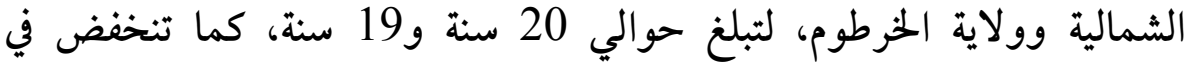

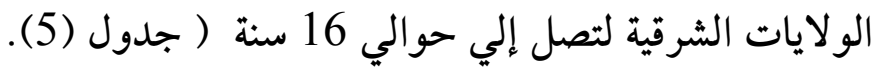

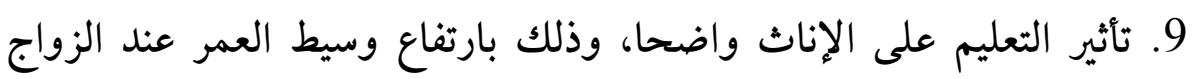

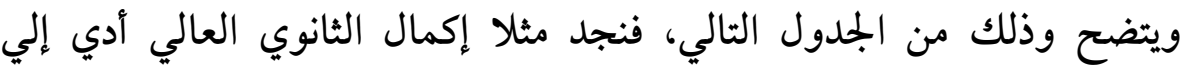
ارتفاع سن الزواج إلي 26 سنة مقارنة بسن المدول 16 سنة لغير المتعلمات. 
جدول (5): متوسط العمر عند الزواج الأول في الريف والحضر والولاية

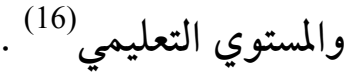

\begin{tabular}{|c|c|c|c|c|c|c|}
\hline \multirow{2}{*}{ سن الزواج } & \multicolumn{5}{|c|}{ الفئات العمريـة } & \\
\hline & $45-49$ & $40-44$ & $\begin{array}{r}35- \\
39\end{array}$ & $\begin{array}{r}30- \\
34\end{array}$ & $25-29$ & \\
\hline 17.3 & 16.3 & 15.8 & 17.5 & 20 & 23.2 & الريف \\
\hline 19.3 & 16.3 & 15.8 & 16 & 16.8 & 19 & الحضر \\
\hline & & & & & & الولايات \\
\hline 19.1 & 16.5 & 16.1 & 17.4 & 19.9 & 23 & الخرطوم \\
\hline 19.9 & 17.5 & 18.5 & 17.8 & 19.8 & 23.35 & الشمالية \\
\hline 16.4 & 15 & 15.3 & 15.2 & 16 & 18.5 & الشرقية \\
\hline 17.5 & 15.4 & 15.5 & 16.2 & 17.2 & 20.6 & الوسطي \\
\hline 17.4 & 16.5 & 15.5 & 15.8 & 18.6 & 20.6 & كردفان \\
\hline 17.9 & 16.9 & 16.5 & 16.7 & 17.2 & 18.2 & دارفور \\
\hline & & & & & & التعليمي \\
\hline 16 & 15.6 & 15.8 & 15.8 & 16.1 & 17.3 & أمي \\
\hline 17.7 & 17.3 & 16.4 & 17.1 & 17.9 & 19 & ابتدائي \\
\hline
\end{tabular}




\begin{tabular}{|r|r|r|r|r|r|r|}
\hline 20.1 & - & - & 21.9 & 19.8 & 20.2 & \\
\hline 22.9 & - & - & 20.3 & 20.9 & 26.7 & \\
\hline 26.4 & - & - & 24.1 & 27 & 27.3 & ثانوي عانوي الكائي \\
\hline 17.8 & 16.3 & 15.8 & 16.4 & 18.1 & 20.5 & \\
\hline
\end{tabular}

ارتفعت نسبة العنوسة في السودان ووصلت إلى (20٪) حسب ما أشارت إليه دراسة حديثة نشرت على موقع (الألوكة الاجتماعي) الذي أشار إلى أن السودان يشترك مع الصومال في هذه النسبة التي ظلت تتزاوج وتتناسل

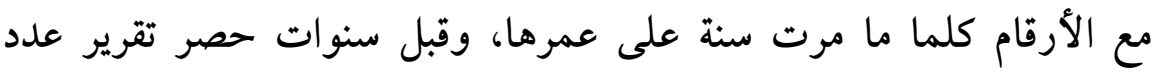
النساء في الفئة العمرية للزواج من (15 إلى 49) سنة بعدد ( مقابل ( 3000650 )، ولم يتخطى التقرير عدد النساء المتزوجات اللائي وصل عددهن إلى ( 6350899 ) امرأة (17)

\section{أسباب العنوسة في السودان :}

هناك أسباب عديدة للعنوسة في السودان منها :

1. الحالة الاقتصادية: وهي تؤثر بشكل مباشر على حالات الزواج وذلك لما يتطلبه من مستلزمات من جهة الرجل (العريس) أو المرأة ( العروس) ، وكما وكا

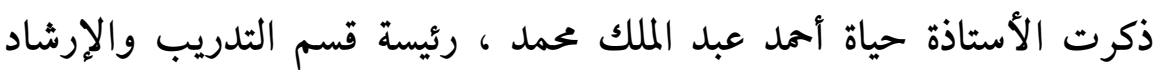

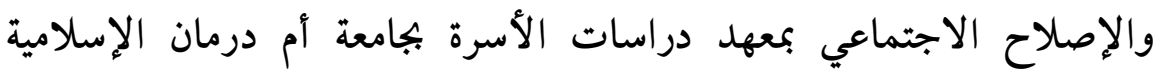

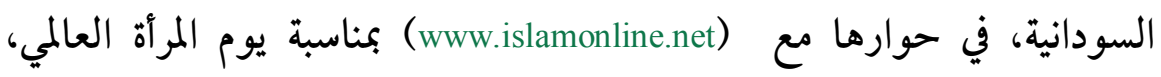

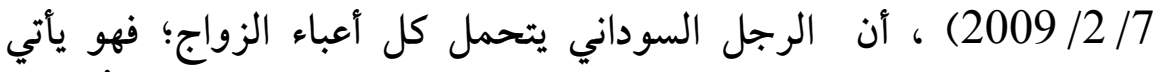
بالشَّبكة، مع مبلغ مالي · ومما يفرض على أم العروس إذا تمت الخِطبة قبل

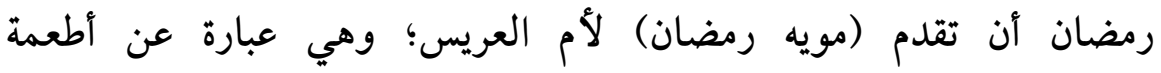

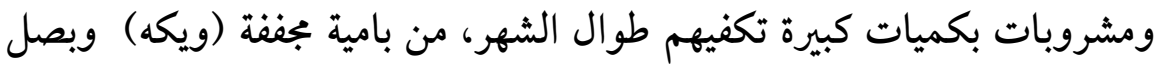


مجفف ولحوم، ومشروب الحلومر، والشاي والقهوة، وبمموعة كاملة من صواني

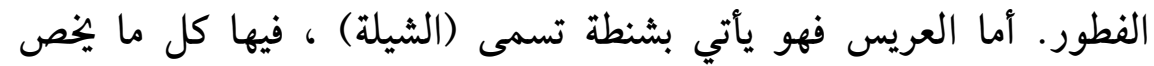
العروسة من الملابس والأحذية والعطور الخاصة بها بكميات كبيرة، وهناك مَنْ

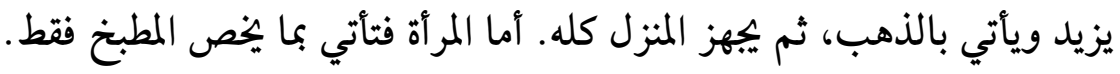
كذلك العامل الاقتصادي يؤثر علي زيادة العنوسة من خلال البطالة

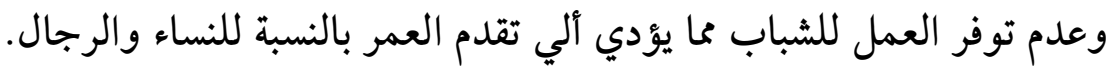
2. غلاء المهور: يطالب الزوج بمهر كبير لا يستطيع توفيره بسهولة، فيواجه الغالبية

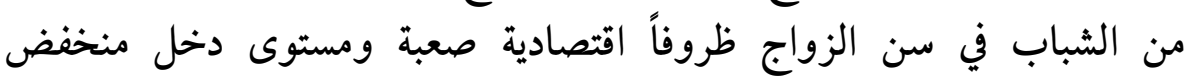

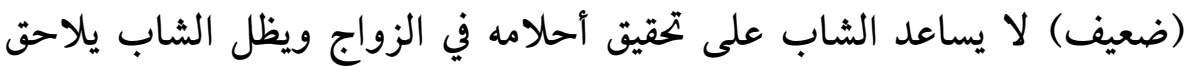

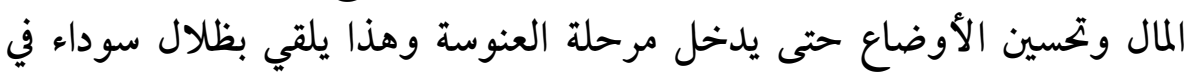
عالم المرأة.

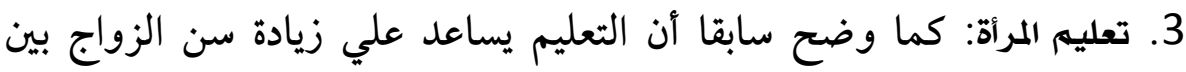

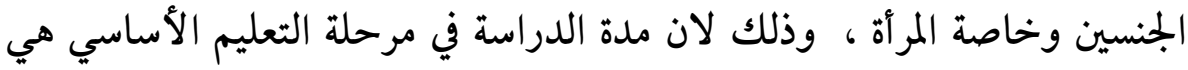

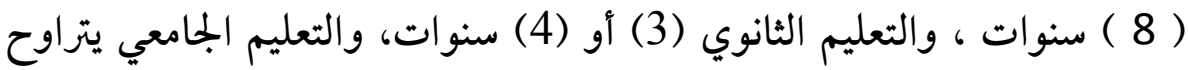

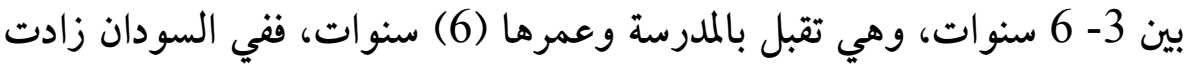

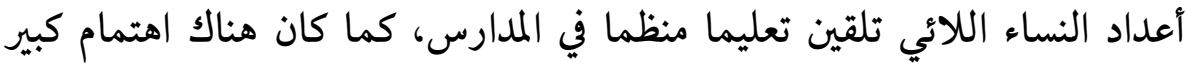

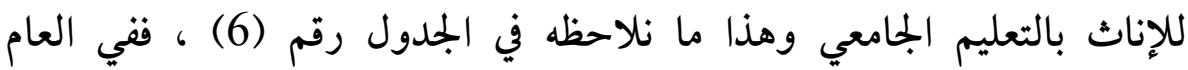

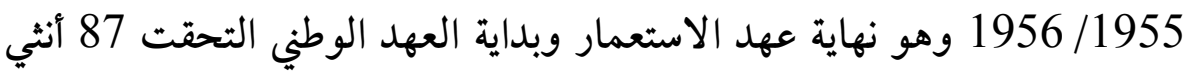

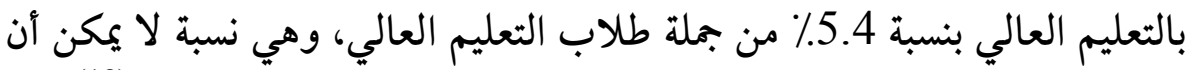

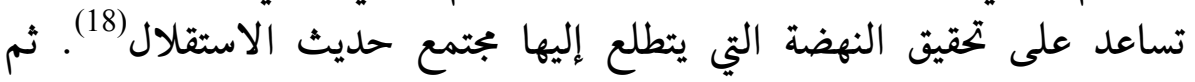

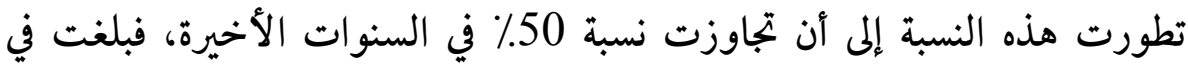

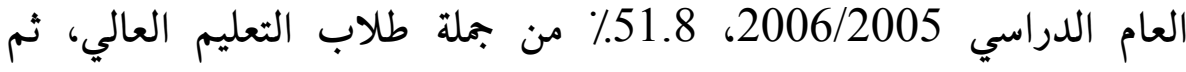
ارتفعت إلى 52.4٪ في العام الدراسي 2008/2007، ثم تراجعت في العامين العادين

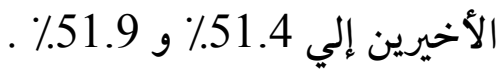




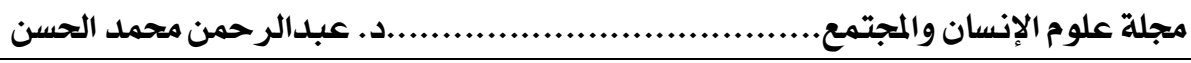

جدول (6) يوضـ عدد الذكور والإناث بمؤسسات التعليم العالي (19)

\begin{tabular}{|c|c|c|c|}
\hline المجموع & الإناث & الذكور & العام الدراسي \\
\hline 1633 & 87 & 1546 & $\begin{array}{r}1956 / 1955 \\
(20)\end{array}$ \\
\hline 78592 & 40750 & 37842 & $2006 / 2005$ \\
\hline 76715 & 40168 & 36547 & 2008 / 2007 \\
\hline 81627 & 41957 & 39670 & $2010 / 2009$ \\
\hline 101775 & 52807 & 48968 & $2011 / 2010$ \\
\hline
\end{tabular}

1996 عيسي 1996

الإدارة العامة للقبول وتقويم وتوثيق الشهادات ، دليل القبول للأعوام المذكورة

دور المرأة السودانية في تقليل العنوسة :

تقوم المرأة السودانية بالعديد من الأدوار و المقترحات التي يعتقد بأن لها

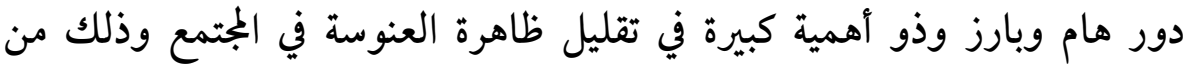

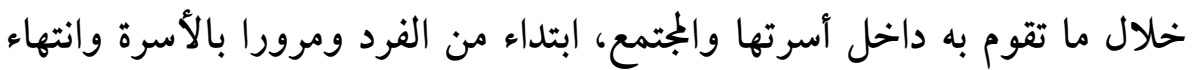

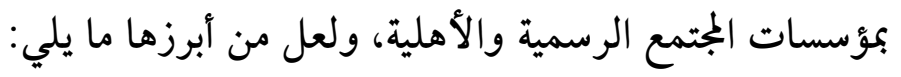
1. أنها تعمل علي تجاوز المظاهر الاجتماعية الزائفة المصاحبة لعادات ومراسم

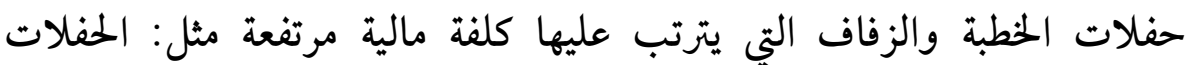

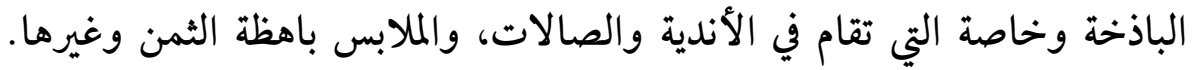

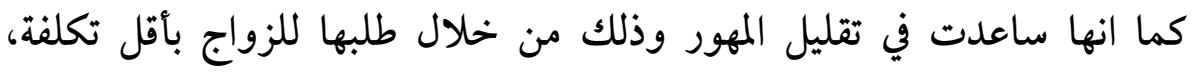
وهذا ما أوضحته فيما يسمي بأغاني البنات والتي نجد فيها عدد كبير يعبر عن 


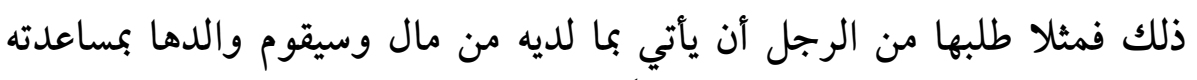

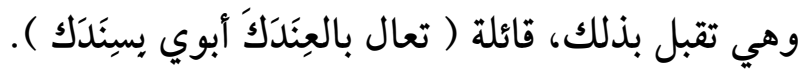

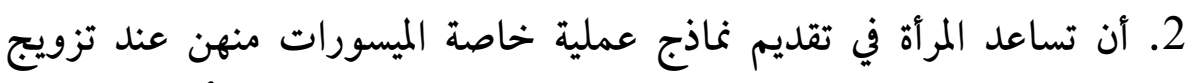

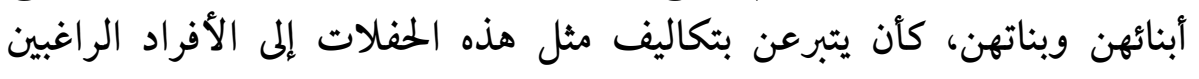

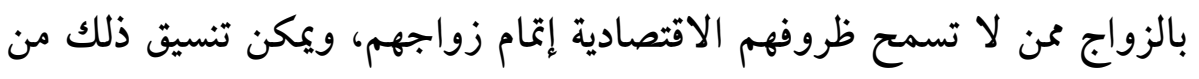
خلال الجمعيات الخيرية.

3. تقديم كافة أنواع الدعم للجمعيات الخيرية حتى تتمكن من تحقيق أهدافها في تيسير سبل الزواج في المجتمع.

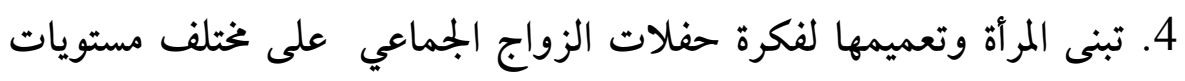

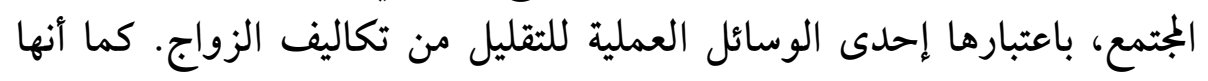

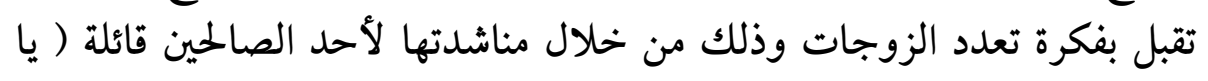

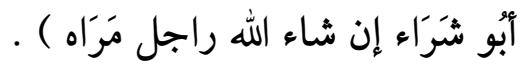


توصلت الدراسة الي عدد من النتائج، ولكن أهمها :

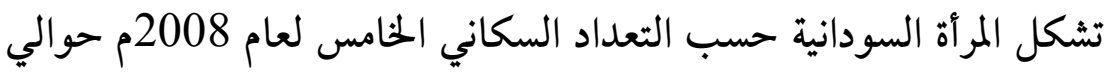

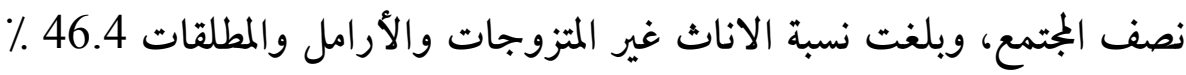

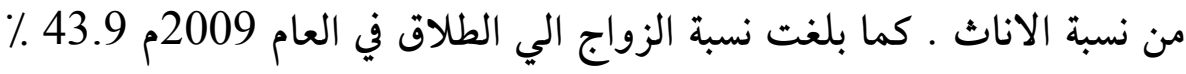

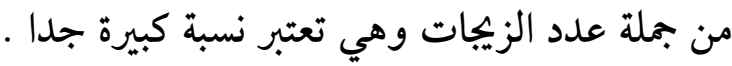

ارتفعت نسبة العنوسة في السودان ووصلت إلى (20٪)، وتوصلت

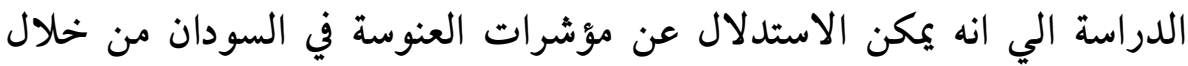

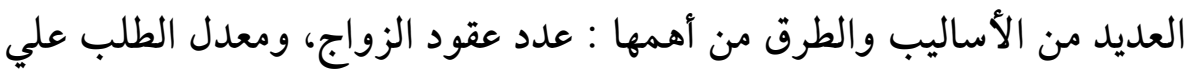

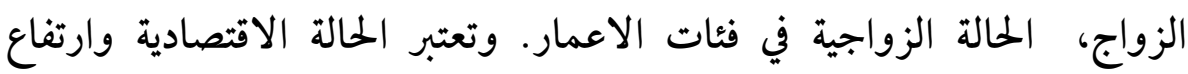

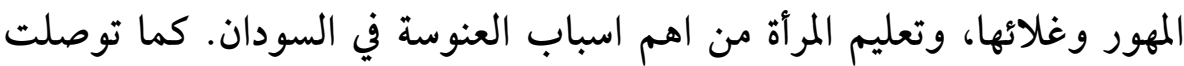

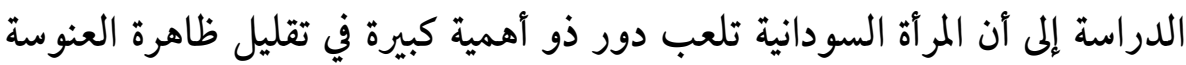

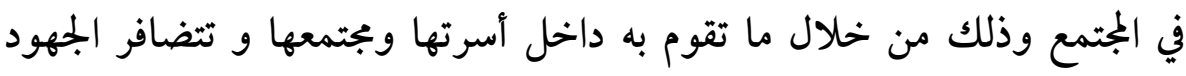

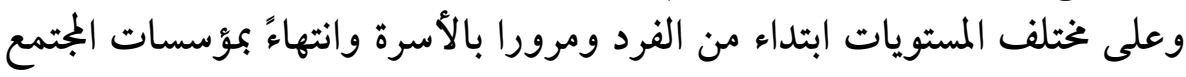
الرسمية والأهلية، ولعل من أبرزها ما يلي:

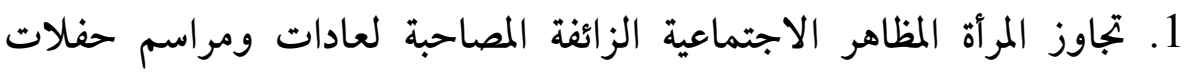
الخطبة والزفاف التي يترتب عليها كلفة مالية مرتفعة.

2. تقديم كافة أنواع الدعم للجمعيات الخيرية حتى تتمكن من تحقيق أهدافها في تيسير سبل الزواج في المجتمع.

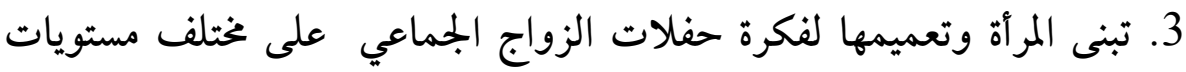

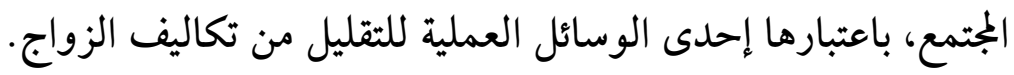

وتوصى الدراسة بضرورة اهتمام المرأة بهذه الظاهرة للتقليل منها وذلك الكيك

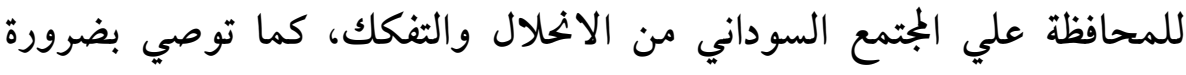


الاهتمام بالجمعيات الخيرية ودعمها حتي تقوم بدورها في اقامة ودعم الزيجات

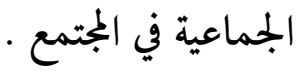
هوامش البحث

همود ، رفيقة سليم ، المرأة المصرية ـ مشكلات الحاضر وتحديات المستقبل، دار الأمين،

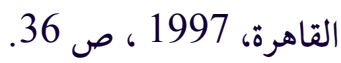

$$
\begin{aligned}
& \text { ابن منظور ، لسان العرب، دار صادر، بيروت، 1992، 1997، ص } 117 . \\
& \text { بممع اللغة العربية، المعجم الوجيز، القاهرة، 2002، ص } 89 \text {. }
\end{aligned}
$$

منصور ، محمد خالد عبد العزيز ، مهلا يا دعاة العنوسة ( دراسة فقهية اجتماعية ) ،

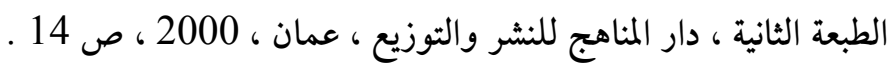

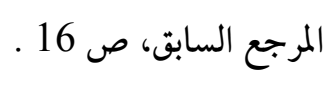

جمال الدين ، نادية ، المراة الريفية وأدوارما الاجتماعية ومحدداتها، ورقة قدمت في ورشة العمل للقيادات النسائية في الفترة من 18 إلى 30 مارس 1995 ،المركز الإقليمي لتعليم

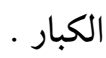

اليونسكو، تقرير عن التربية في العالم، منشورات اليونسكو، باريس ، 2000 ، ص

عمار، حامد، بناء الإنسان العربي، مركز ابن خلدون للدراسات الإنمائية، القاهرة ،

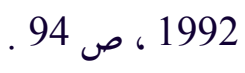

الجهاز المركزي للإحصاء، تعداد السكان الخامس، 2010 ـ

$$
\text { المرجع السابق. }
$$


عبد المجيد، احمد محمد، الطلاق واثثه علي الأسرة والمجتمع، ورقة علمية مقدمة

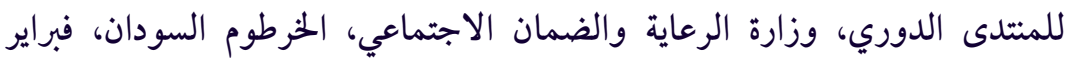
2011 طه، احمد ( 1998 ) ، السكان والتنمية، الكتاب المرجعي في التربية السكانية ، الشركة

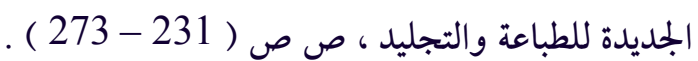

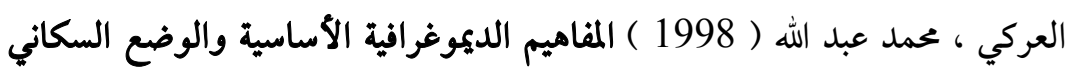
في السودان ، الكتاب المرجعي في التربية السكانية، الشركة الجديدة للطباعة والتجليد ، ص ص 11 - 114 طه أحمد، مرجع سبق ذكره. الجهاز المركزي للإحصاء، تعداد السكان الرابع درهن 1993 ـ تقرير السودان عن السكان والتنمية 1994م . صحيفة الراكوبة الالكترونية، الاثنين 27/ 209 / 2010 م . عيسي، سعاد إبراهيم، مسيرة التعليم العالي في السودان ( 1898-1987م ) ) ، دار الخرطوم للطباعة والنشر ، الخرطوم ، 1996، ص 36.

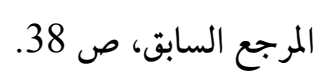
الإدارة العامة للقبول وتقويم وتوثيق الشهادات للأعوام( 2005 ) ، ( 2007 ) ، ( ) 2009 )، ( 2010 ) 